\title{
Heat Treatment Simulation for Low Pressure Hyper Carburizing Process
}

\author{
Tsuyoshi Sugimoto ${ }^{1}$ and Dong-Ying Ju${ }^{2}$ \\ 1. Nissan Motor Co., Ltd., Atsugi, Kanagawa, Japan \\ 2. Saitama Institute of Technology, Fukaya, Saitama, Japan
}

\begin{abstract}
Carburizing heat treatment is well used to increase the strength of gears and automobile drivetrain parts. When very high contact fatigue strength is required, hyper carburizing or carbonitriding is well used to improve the surface hardness and tempering softening resistance. Over saturate carburizing as called hyper carburizing can be used in a conventional ordinary carburizing furnace and investment of new gas supply equipment is unnecessary, while there are problems such as controlling precipitation of cementite and securing hardenability of the surface, etc. Also, problems such as secondary precipitation to control the material micro structure, its quality prediction method becomes important. In recent years the low pressure carburizing method has been widely used and the possibility of making hyper carburizing in low cost has been expanding. However, when hyper carburizing is performed by low pressure carburizng, reticulated cementite occurs at the edge of the part, there is a problem such as local increase of carbon concentration distribution and toughness. In this study, we tried to formulate precipitation when super carburizing was performed on steel parts using a low pressure carburizing furnace, formulated the surface hardness distribution, and tried to calculate the hardness and cementite precipitation size distribution. CALPHAD method is used to obtain the physical property values, graphite of an intermediate product was precipitated from the low pressure carburizing atmosphere on the surface layer, and it was assumed that carburization occurred therefrom. Estimating supersaturated carbon precipitates as cementite, the growth amount of the precipitate is calculated. The deposition rate was estimated by comparing the actual measurement with the calculated value. Estimating hardness is determined by the sum of the hardness of the precipitate and the hardness of the parent phase part, the hardness distribution was verified. As a result, the hardness distribution at the time of high concentration carburization in the test piece shape was predicted. The method was also applied to the actual part shape, and the quality difference between the edge part and the flat part of the gear and the heat treatment deformation quantity were estimated.
\end{abstract}

Key words: Heat treatment simulation, low pressure carburizing, hyper carburizing, cementite precipitation.

\section{Introduction}

To increase the strength of gear parts for automobiles, improvement of hardness, durability against decrease in hardness during use, and improvement in temper softening resistance become issues [1]. To avoid such phenomena, techniques such as carbonitriding or hyper carburizing are often used. However, conventionally, in case of hyper carburization, there is a problem that the treatment time is several times as long as the ordinary carburizing method, and in the case of carbonitriding, a separate nitrogen supply

Corresponding author: Tsuyoshi Sugimoto, in Material Engineering Department, research fields: heat treatment, metal material, computational simulation for materials. device is required, which is expensive.

Since the low pressure carburization method has become popular in recent years and it has become easy to introduce high concentration carbon exceeding the cementite solubility limit on the metal part surface, it becomes possible to shorten the processing time drastically with hyper carburization [2]. However, since low pressure carburizing has large shape dependence [3], there is a characteristic that the carbon concentration is large in the edge part, the flat part and the concave part of the part, and its shape dependency becomes a problem even if high carburization is performed by low pressure carburization.

In this research, we tried quality prediction by simulation of low pressure hyper carburizing, which 
should consider these shape dependencies. We tried to predict the carbon concentration distribution, precipitate amount, hardness which is a problem in terms of quality with the disk test piece shape. We also predicted the actual gear shape and examined the carburizing conditions to suppress the quality difference at the edge part and the flat part tooth bottom part.

\section{Experimental Procedure}

To compare experimental and simulation result described later, gear-shaped samples of JIS SCM20H shown in Table 1 were subjected to hyper carburizing under the conditions shown in Fig. 1. The first half before intermediate cooling is called primary carburizing, and the subsequent part is called secondary precipitation process.

As for the carburizing condition, in the flat part, as shown in Fig. 1, the cementite precipitated carbon concentration was set to $1.5 \mathrm{Cwt} \%$ which does not become hyper eutectoid at the carburizing temperature, co-segregation at the flat part and hyper eutectoid at the edge part I made it to be. After that, the part was cooled once and then subjected to precipitation treatment under two conditions shown in Fig. 1. The hardness was measured after secondary precipitation. Likewise, the amount of precipitates was specified after secondary precipitation process, and how precipitation progresses during carburization and secondary precipitation was specified.

\section{Simulation Procedure}

The carburizing on process, precipitation and hardness is calculated by heat treatment simulation.

The precipitation model in response to the above experiment and the formulated equation up to the second precipitation was examined. At the time of primary carburizing, the surface reaction of carburizing was determined according to Morita and Hanyuda [4], and carburization occurred with cementite and graphite as intermediate products.

\begin{tabular}{ll} 
Table 1 & \\
\hline Gear type & Hypoid gear \\
Module & 3.12 \\
Target ECD & $0.9 \mathrm{~mm} @$ pitch point \\
Material & JIS SCM420H \\
\hline
\end{tabular}

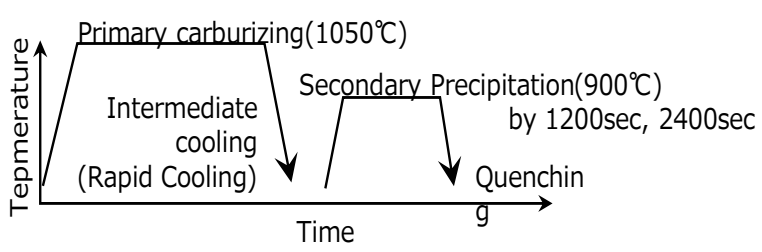

Fig. 1 Heat treatment conditions.

It was assumed that the carbon concentration exceeding the saturated carbon concentration at the secondary precipitation treatment temperature contributes to cementite precipitation. It was assumed that cementite precipitation increased from existing precipitation nuclei as a starting point and particle size increased with diffusion rate growth formulation.

In addition to the calculation of precipitation hardness was predicted. Hardness predicted separately for matrix phase and cementite phase, and predicted total hardness by taking weighted sum of these. The hardness of the matrix phase was examined from the sum of each phase (martensite, banite, ferrite and pearite) and cooling calculation on quenching with carbon concentration value taken into consideration, and the hardness of cementite was assumed to be constant. It is assumed that the overall hardness rises as the increase of cementite is effected by increasing in cementite grain size.

The actual calculation method was carried out by the method shown in Fig. 2. The cementite-graphite precipitation content at treating temperature for treatment temperature was calculated using Open Calphad. Using this result, carbon diffusion at primary carburization was calculated by SFTC DEFORM-HT ${ }^{\circledR}$ and carbon concentration distribution after primary carburization was obtained. The difference between the carbon concentration after the primary carburization and the cementite equilibrium carbon concentration at the secondary precipitation temperature was determined 


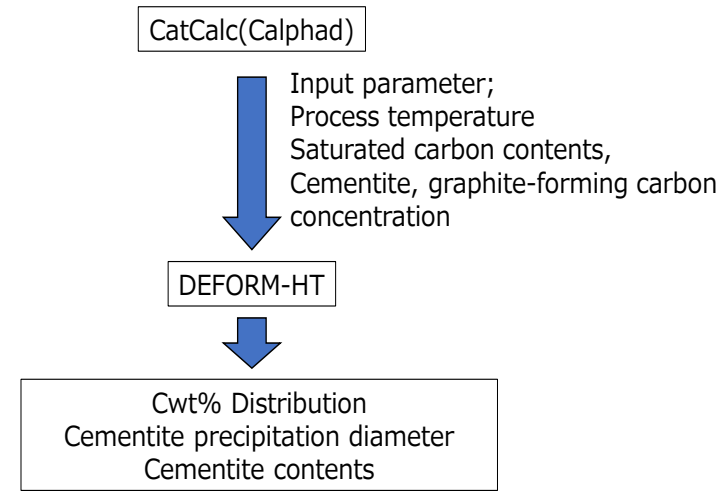

Fig. 2 Schematic of hyper curburizing simulation.

and used as the driving force for the diffusion rate growth during the secondary precipitation.

For grain growth during secondary precipitation, calculations were performed with DEFORM-HT ${ }^{\circledR}$ using a user function incorporating diffusion rate growth. After secondary diffusion, quenching analysis was carried out to determine the hardness distribution of the matrix phase. By obtaining this weighted sum of cementite hardness distribution and cementite amount, the hardness distribution after high concentration carburization was obtained.

\section{Result}

\subsection{Verification on Primary Carburization}

Fig. 3 shows changes in carburizing temperature, cementite precipitated carbon concentration and solid solution carbon concentration. As the treatment temperature rises, it can be seen that the solid soluble carbon concentration is rising. In vacuum carburizing, the pulse carburizing method is often used in many cases. In this case, it was assumed that carbon flowing in cementite equilibrium occurred at the surface of the pulsed carburizing gas, and surface reaction did not occur at the time of pulse when nitrogen gas was flowing. Carbon concentration diffusion inside the part was calculated according to Fick's second law as shown in Eq. (1). The diffusion multiplier was in accordance with Well et al. [5].

$$
D(C, T)=e^{\left(18.5-1.5 C+\frac{546 C^{2}+2361 C-19410}{T}\right)}
$$

$C_{0}$ : surface carbon contents;

$C$ : carbon contents;

$T$ : temperature.

The calculated results are shown in Fig. 4. The comparable experimental carbon content is shown in Fig. 5. In this case, carburization was carried out at $1,050{ }^{\circ} \mathrm{C}$., the conditions of the pulse were determined so that the carbon concentration on the surface became approximately $1.5 \mathrm{Cwt} \%$, and carburization was carried out. The carbon concentration distribution in the flat part was in good agreement with experiment and analysis. In addition, excessive carburization phenomenon at the edge portion, which is a problem for gear parts, was well reproduced.

\subsection{Verification on Secondary Diffusion}

It was assumed that precipitation during secondary diffusion follows diffusion rate growth [6,7]. Diffusivity growth is a precipitation mode assuming that particles precipitate according to the formula shown in Eq. (2), and it is a precipitation mode
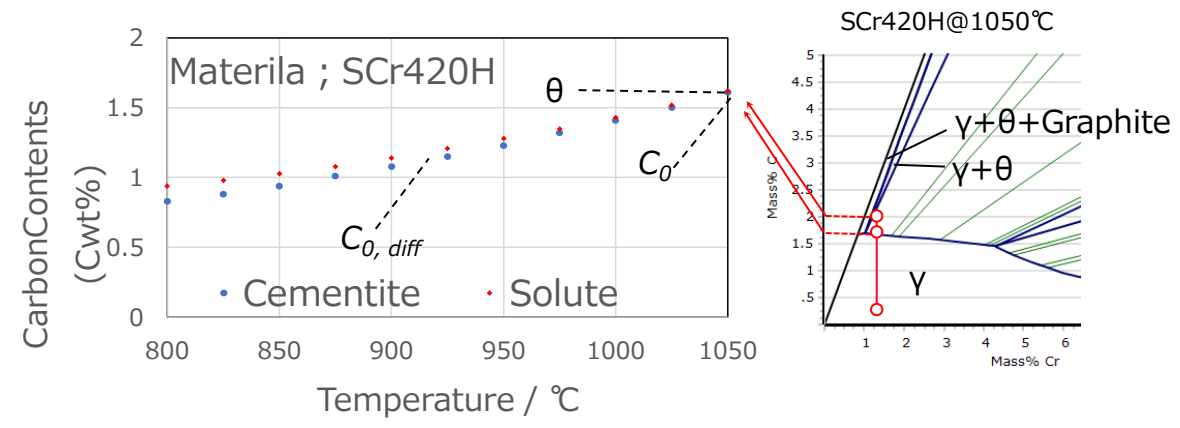

Fig. 3 Solutable contents calculated by calphad method. 


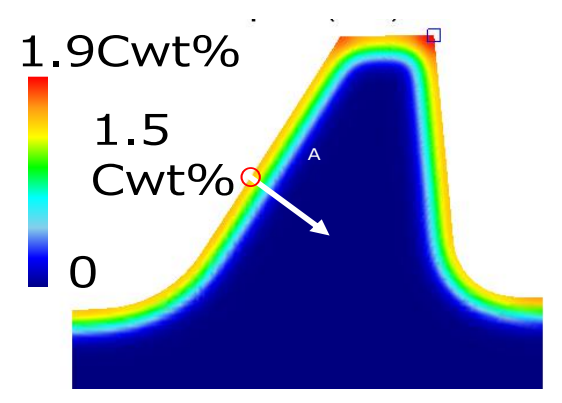

Fig. 4 Carbon contents distribution after primary carburizing.

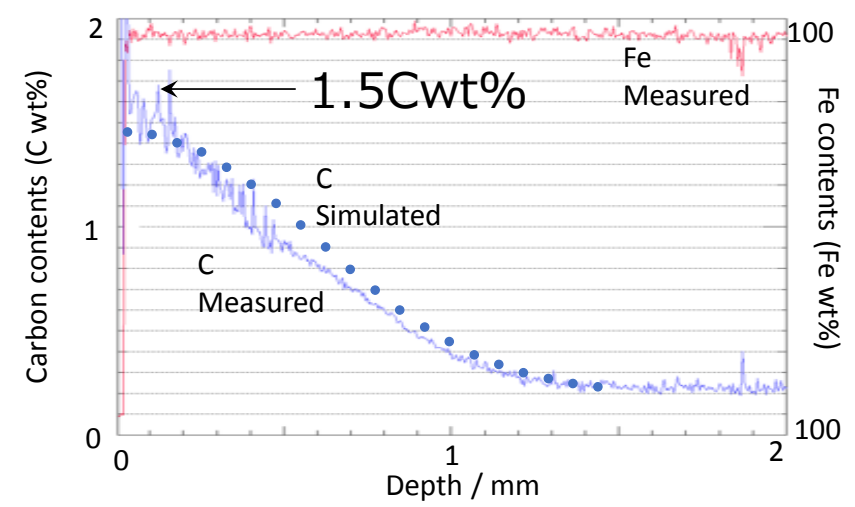

Fig. 5 Carbon and Fe contents distribution on position $\mathrm{A}$ as shown in Fig.4.

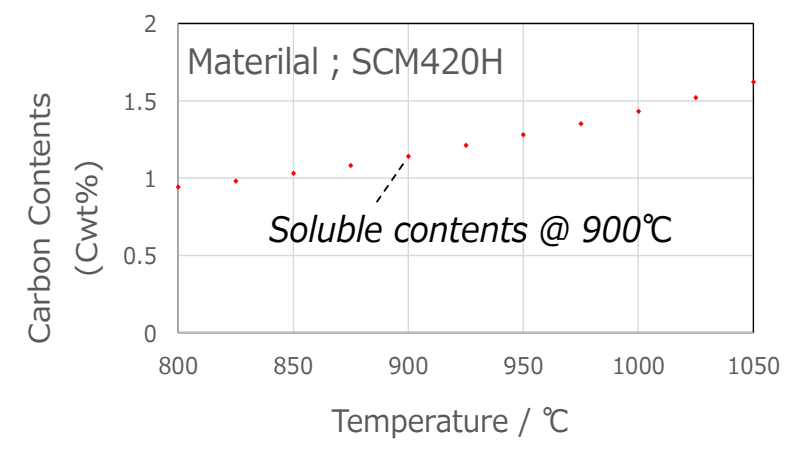

Fig. 6 Solutable contents calculated by calphad method.

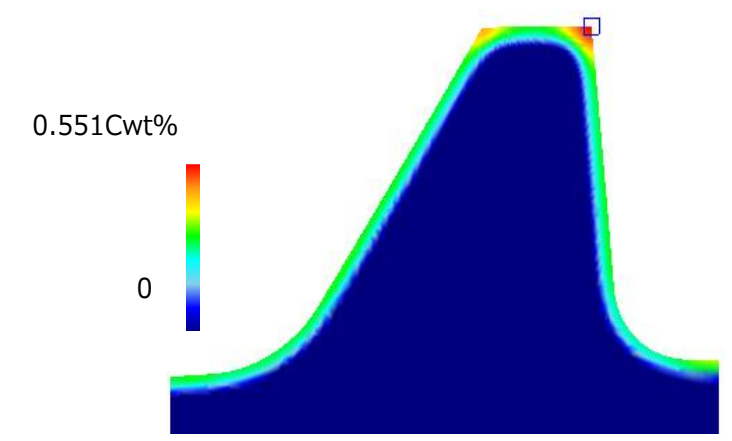

Fig. 7 Precipitation driving force.

assuming that the elements migrate and precipitate from the surrounding area where precipitation nuclei already exist.
Precipitation diameter; $r=K(D t)^{0.5}$

$D$ : Precipitation driving force $(\mathrm{Cwt} \%)$;

$t$ : Secondary diffusion time(s);

$K$ : constant depend on each condition.

The movement amount of the element was estimated by the subtract from carbon contents to soluble contents at secondary diffusing temperature as shown in Fig. 6. The Precipitation driving force distribution is shown in Fig. 7.

Fig. 8 shows the results of the distribution of the precipitate particle size calculated in the present case. Fig. 9 shows comparing result between experimental and simulation on precipitation diameter. at $K=3.6 \times$ $10^{\wedge}-3$. It is roughly reproduced that the cementite particle size at the edge portion is large. Even in experiments, the precipitate grains grew depending on time, and the growth curve between the experimental value and the calculated value became close.

\subsection{Hardness Distribution after Secondary Precipitation}

Fig. 10 shows the state of the hardness distribution after hyper curbrizing. Fig. 10a is the hardness 
distribution caused by matrix phase hardening. Fig. hardness distribution roughly agrees with the $10 \mathrm{~b}$ is the hardness distribution caused by cementite experimental value and the calculated value as shown precipitation. The total hardness is calculated by the in Fig. 11, and the hardness of the high concentration sum of hardness of cementite and matrix phase. The carburization can be predicted in advance by this case.

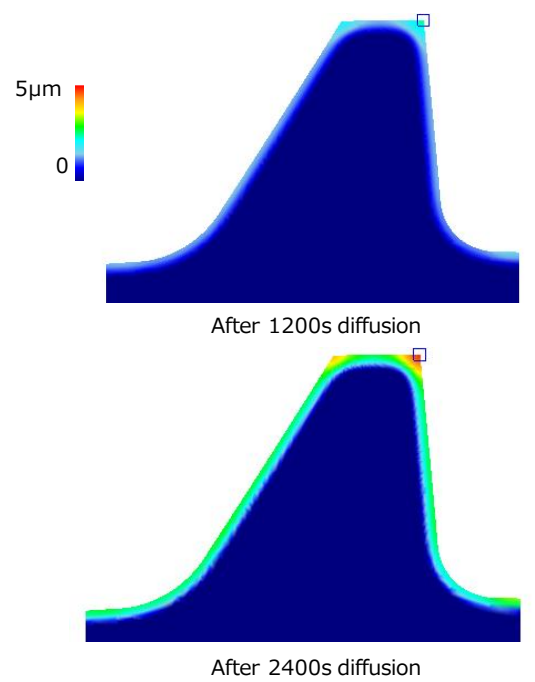

Fig. 8 Precipitation diameter distribution on secondary diffusion.

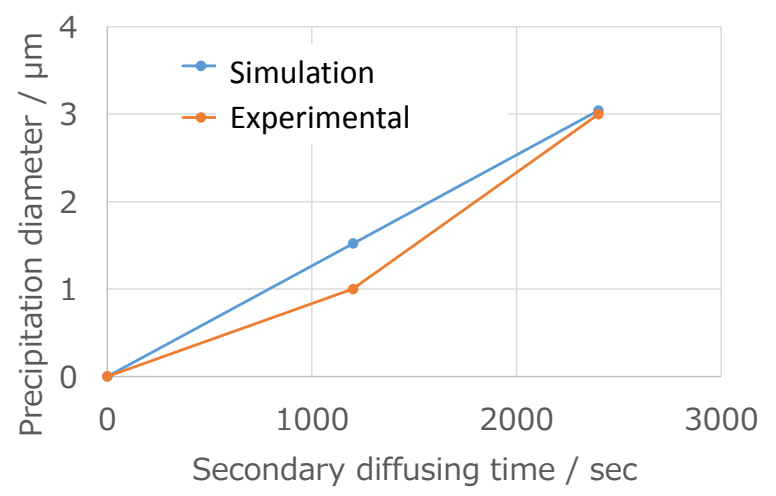

Fig. 9 Precipitation diameter change on secondary diffusion.

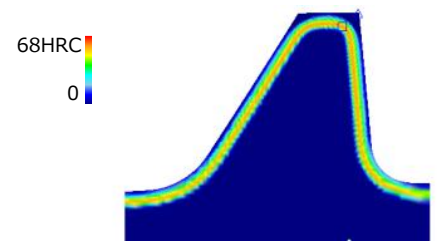

(a) Hardness caused by mother phase
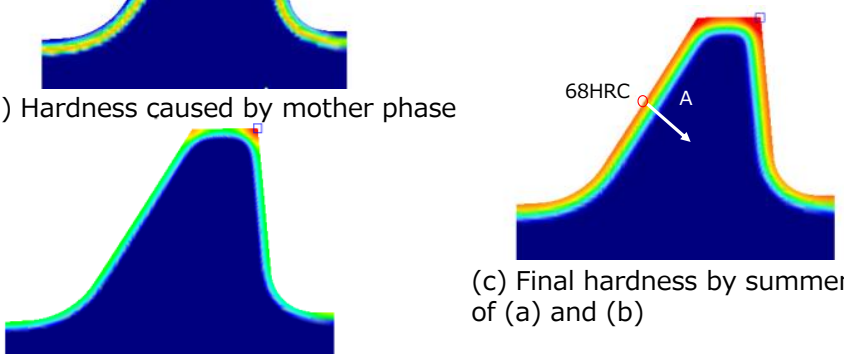

(c) Final hardness by summention of (a) and (b)

(b) Hardness caused by cementite

Fig. 10 Hardness distribution after secondary precipitation. 


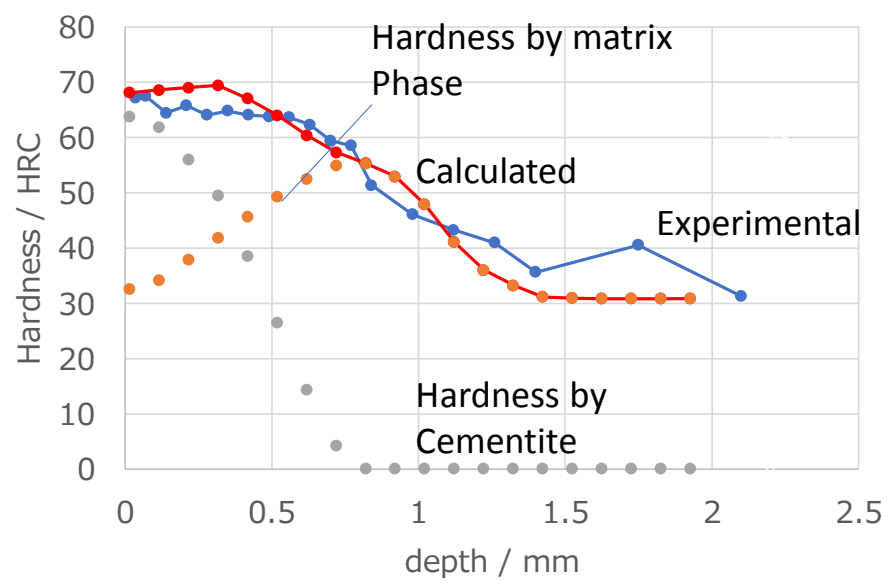

Fig. 11 Experimental hardness distribution on point $\mathrm{A}$.

\section{Discussion}

Hyper carburizing heat treatment of the gear parts was carried out by the secondary precipitation method on low pressure carburizing process. After heating and secondary precipitation conditions were changed to several kinds, after quenching, macrostructure, hardness distribution, and precipitation state of precipitates after quenching were investigated with a microscope, hardness tester.

At the same time, the state of low pressure carburizing was calculated by the carburizing heat treatment simulation using SFTC DEFORM-HT ${ }^{\circledR}$ and the situation of precipitation of cementite at the time of the secondary precipitation was predicted.

By conducting the condition derivation by carburizing heat treatment simulation at the time of low pressure super carburization, prediction method of carbon concentration non uniformity, net mesh precipitation of meshes, which is a problem of the same construction method, was studied. By using this method, it is possible to investigate material conditions and heat treatment conditions to suppress these problems.

\section{Conclusion}

To investigate the conditions for applying low pressure hyper carburizing to the actual part shape, the quality simulation method was performed. Carbon content distribution analysis that reflects the dependence of the actual part shape can be carried out by conducting the carbon concentration diffusion analysis incorporating the precipitation condition using the CALPHAD method together. We succeeded in macroscopically predicting precipitation particle size and hardness by conducting a secondary precipitation analysis using the carbon amount exceeding the eutectoid carbon concentration similarly determined by the CALPHAD method as the precipitating dynamics.

However, in this method, although it is possible to consider the carbon concentration and the average grain size of the precipitate, it is considered that the cementite excess carburized structure which is a feature of the vacuum carburization generated at the time of primary carburization, the cementite originating from the grain boundary or the like occurring at the secondary carburization. It is impossible to predict micro suggestive phenomena such as segregation of grain boundaries of grains. In the future we plan to continue our research on methods to make these statistical mechanics predictions possible.

We will also investigate the quality which becomes important for determining the heat treatment conditions such as deformation volume and residual stress based on this method. 


\section{References}

[1] Abe, S., and Ikeda, S. 2004. "High Pitting Fatigue Strength Steels Based on Super-carburizing." Kobe Steel Engineering Reports 54 (3): 21-4.

[2] Todo, S., Imataka, H., and Sueno, H. 2016. "Development of Application Technology for Vacuum Carburizing" Japan Steel Engineering Report 406: 13-8.

[3] Jones, K. D., and Krauss, G. 1980. "Effect of High-Carbon Specimen Corners in Microstructure and Fatigue of Partial Pressure Carburized Steels." Heat Treat 79: 188.

[4] Morita, T., and Hanyuda, T. 2006. "Prediction of Carbon Profiles in Vacuum-carburized Steels Based on
Carburizing Mechanism.” Tetsu-to-Hagane 92 (4): 36-41.

[5] Well, C., Batz, W., and Mehl, R. F. 1950. “'Diffusion Coefficient of Carbon in Austenite." Trans. AIME 188: 553.

[6] Klein, S., Mujica, L., Walter, M., Weber, S., and Theisen, W. 2017. "Diffusion Processes during Cementite Precipitation and Their Impact on Electrical and Thermal Conductivity of a Heat-Treatable Steel." J Mater Sci 52: 375-90.

[7] Tanaka, K., Ikehata, H., Takamiya, H., and Mizuno, H. 2011. "Calculation of Microstructure in Vacuum-carburizing Incorporating Kinetics Modeling of Grain-Boundary Cementite." Tetsu-to-Hagané 97 (3): $32-7$. 